\title{
Tierno Monénembo, Le roi de Kahel
}

\section{Elena Pessini}

\section{OpenEdition}

\section{Journals}

\section{Édition électronique}

URL : http://journals.openedition.org/studifrancesi/8104

DOI : 10.4000/studifrancesi.8104

ISSN : 2427-5856

\section{Éditeur}

Rosenberg \& Sellier

\section{Édition imprimée}

Date de publication : 1 juillet 2009

Pagination : 450

ISSN : 0039-2944

\section{Référence électronique}

Elena Pessini, «Tierno Monénembo, Le roi de Kahel », Studi Francesi [En ligne], 158 (LIII | II) | 2009, mis en ligne le 30 novembre 2015, consulté le 08 janvier 2021. URL : http://journals.openedition.org/ studifrancesi/8104; DOI : https://doi.org/10.4000/studifrancesi.8104

\section{Ce document a été généré automatiquement le 8 janvier 2021.}

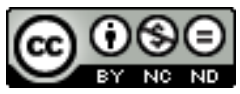

Studi Francesi è distribuita con Licenza Creative Commons Attribuzione - Non commerciale - Non opere derivate 4.0 Internazionale. 


\title{
Tierno Monénembo, Le roi de Kahel
}

\author{
Elena Pessini
}

\section{RÉFÉRENCE}

TIERNO MONÉNEMBO, Le roi de Kahel, Paris, Seuil, 2008, pp. 262.

Difficile de ranger sous une étiquette le dernier roman de l'écrivain guinéen Tierno Monénembo. Il s'agit à la fois d'une libre interprétation de la vie d'Aimé Victor olivier de Sanderval, de la biographie romancée d'un personnage hors du commun qui se mit en tête, à la fin $\mathrm{du}_{\mathrm{xIx}} \mathrm{e}^{\mathrm{siècle}}$, de fonder son propre royaume en Afrique, au Fouta Djalon, et de faire bénéficier ses futurs sujets africains de toutes les découvertes philosophiques, scientifiques et techniques de la civilisation occidentale. Il est entre autres obsédé par l'idée de faire construire une ligne de chemin de fer qui sortirait le pays de son isolement. L'homme a bien existé; la phrase de l'auteur qui ouvre le récit: «Merci à M. et Mme Bruno Olivier de Sanderval de m'avoir gracieusement ouvert leurs archives», veut en être la preuve. Il a même écrit des carnets de voyage qui témoignent de ses différents séjours en Afrique. Mais, à ce fond de réel anecdotique et historique, Monénembo mêle les rythmes du roman d'aventure que constitue le récit des cinq voyages d'Aimé Victor Olivier, surnommé Yémé par les Peuls, sur le continent africain. Les dangers et les empêchements qui distinguent le roman d'aventure sont ici employés à foison: nature hostile, faune dangeureuse, peuples aux mœurs totalement différentes dont il faut adopter les ruses, les rites, la conception du temps, l'organisation tribale... Pourtant, la ténacité d'Aimé de Sanderval, son obstination et son désir fou d'obtenir une parcelle de terre à laquelle il a l'impression d'appartenir un peu plus chaque fois qu'il l'aborde, lui permettront d'exaucer partiellement ses vœux; les Peuls le reconnaîtront comme un des leurs, l'almâmi (le chef suprême du royaume) lui concédera son amitié ainsi qu'un morceau de terre, Kahel, dont il pourra disposer à sa guise, où il battra sa propre monnaie à son effigie et contribuera au développement de l'actuelle ville de Conakry. Tierno Monénembo mène son histoire avec le talent qu'on lui connaît de grand narrateur, de dessinateur de personnages qui entourent, dans un parfait équilibre, le protagoniste. Et la France? Elle semble représenter un obstacle plus 
insurmontable que la jungle africaine et entrave les visées originales de Monsieur de Sanderval. Monénembo prend un malin plaisir à décrire les démêlés de l'explorateur avec l'administration coloniale parisienne qui est en train de se constituer dans la capitale mais qui n'a aucune idée du terrain. La lutte sera sans merci entre la nation française, qui dispute des territoires coloniaux aux Anglais et ne reconnaîtra jamais la domination personnelle d'un de ses citoyens, et Sanderval qui ne comprend pas, ou feint de pas comprendre, ce qu'on lui reproche. Les cinq allers et retours France-FoutaDjalon que l'auteur documente tout au long du livre nous permettent de saisir l'énorme écart qui sépare les deux continents, les deux cultures que malgré ses lubies et ses projets irréalisables, Sanderval a réellement voulu mettre en contact. Pour obtenir Kahel, Sanderval a vraiment dû devenir Peul, un Peul parmi les autres; l'assimilation a eu lieu en sens inverse. Cette aventure donquichottesque, et fantastique par certains aspects, constitue une autre tesselle de la mosaïque historique africaine que l'œuvre de Tierno Monénembo s'attache à reconstituer. 